\title{
TITLE: IS OBSTETRIC OUTCOME RELATED TO LOCAL ANESTHESIA CONCENTRATION?
}

AUTHORS: Mojgan Davallou MD, Stephen H. Halpern MD MSc, Jennifer Yee BSc N, Pamela A Angle MD MSc, Samuel Tang MD, BSc.

AFFILIATION: Department of Anaesthesia, Sunnybrook and Women's College Health Sciences Centre and the University of Toronto. 76 Grenville St. Toronto, Ontario M5S1B2.

INTRODUCTION: Studies comparing epidural to parenteral opioid analgesia demonstrate an increase in instrumental vaginal delivery (IVD) in the epidural group (1). None of these studies were blinded and so it is possible the increase was due to a change in physician behavior rather than a biologic effect. There are a number of studies that compared high concentration (HC) to low concentration (LC) local anesthetics. Therefore it may be possible to establish a concentration dose-response relationship. Earlier work has shown an increase in forceps delivery when HC local anesthetics were compared to very dilute solutions (2). In this metaanalysis we broadened the definition of low and high concentrations to conform to the authors definitions.

METHODS: We searched electronic databases and bibliographies (including manual searches) to September 2004, MESH terms and text words for epidural analgesia, labor analgesia, local anesthetic concentration, forceps delivery, and cesarean section. We included RCTs that compared LC to HC local anesthetics for labor analgesia. Only studies that compared the same local anesthetic with (or without) the same additives were included. The studies were rated for quality (3). The primary outcome was IVD. The outcomes were combined using meta-analytic techniques. An odds ratio $<1$ favored LC. A p $<0.05$ was considered statistically significant.

RESULTS: 16 studies in 14 manuscripts met our criteria (studies available from the authors). There were 1914 patients in the LC groups and 1259 patients in the HC group. The median quality score was three. Twelve studies were blinded. The concentration of local anesthetic was between $0.5 \%$ and $0.06 \%$. There was a substantially increased risk of ISV in the HC group $(\mathrm{OR}=0.69,95 \% \mathrm{CI}=0.59--0.81, \mathrm{p}<0.0001$, Figure $)$. This was reflected by an increased incidence of spontaneous delivery in the LC group $(\mathrm{OR}=1.38,95 \% \mathrm{CI}=1.38--1.60, \mathrm{p}<0.0001)$. The incidence of $\mathrm{C} / \mathrm{S}$ was identical in the groups $(\mathrm{OR}=1.01,95 \% \mathrm{CI}=0.84-1.22, \mathrm{p}=0.93)$.

CONCLUSION: The data from our meta-analysis show that the use of LC consistently reduces the incidence of IVD. We therefore recommend the use of LC local anesthetic whenever possible.

\section{REFERENCES:}

1. Am J. Obstet Gynecol 2002;18 5S69-S78.

2. Can J Anesth 2002;49:A58

3. Controlled Clinical Trials 1996;17:1-12. 